\title{
Queer English Language Teacher Identity: A Narrative Exploration in Iran
}

\author{
Fakhereh Safatian (Corresponding author) \\ Department of foreign languages, Kharazmi University \\ No.43, South Mofatteh Ave, Tehran, Iran
}

Received: July 1, 2020 Accepted: July 28, 2020 Published: July 30, 2020

doi:10.5296/jsel.v8i1.17452ＵRL: https://doi.org/10.5296/jsel.v8i1.17452

\begin{abstract}
This qualitative study explores the narratives of a queer female English teacher to understand (a) how Iranian cultural, familial, and relational discourses influence feelings of "belonging" for queer Iranian women, and (b) how queer Iranian women cope with the challenges of being both LGBTQ and Iranian. Interviews were analyzed using grounded theory analysis, revealing that queer Iranian women experience feelings of cultural isolation as a result of the homosexual identity delegitimization that is often perpetuated within the Iranian community. The Participant copes by creating cultural distance between herself and the Iranian community when she experiences this isolation.
\end{abstract}

Keywords: Identity, language teacher identity, Queer identity 


\section{Introduction}

All through the previous century, women have met up, drawing from the quality of their common encounters to battle for sexual orientation uniformity and social equity, perceiving that "the political requests of millions talk more capably than the supplications of a couple of detached voices" (Crenshaw, 1991, p. 1241). As Crenshaw (1991) takes note of, "this procedure of perceiving as social and foundational what was some time ago apparent as separated and individual has likewise portrayed the character governmental issues of African Americans, others of shading, and gays and lesbians, among others" (pp. 1241-1242). While intergroup collusions might be pivotal to the achievement of social developments, such character governmental issues will in general disregard or conflate intragroup dissimilarities. This is tricky since the difficulties that numerous women experience are formed by different components of their characters and how those personalities converge (Crenshaw, 1991). For instance, Moraga (1997) places, "In this nation, lesbianism is a neediness - as is being earthy colored, as is being a woman, as is by and large outright poor... The threat lies in neglecting to recognize the particularity of the mistreatment" (p. 29). That's right (2010) in this manner calls for intercultural researchers to receive an intersectional approach when directing intercultural correspondence research, Thick intersectionalities require an investigation of the mind boggling particularities of people's lives and identities related with their race, class, sex, sexuality, and national areas by understanding their history and personhood in solid existence, and the transaction between singular subjectivity, individual organization, fundamental game plans, and auxiliary powers. It requests that we focus on the lived encounters and accounts of the people occupying a specific crossing point without assumptions of qualities, philosophies, and legislative issues. (p. 173)

We have as of late observed a pattern in works gave to adoring the profound complexities of people's characters while looking at correspondence forms (eg, Holling and Calafell, 2011; Nakayama and Halualani, 2010). Truly, most investigations in the sociologies and humanities (eg, correspondence examines, humanism, strange examinations, political theory, and so forth.) had focused on the sexual personalities of white gay men, regularly barring ethnic minorities, especially women of color, from their examinations (Parks, Hughes, and Matthews, 2004). The examination that concentrated on lesbian identity was commonly centered around white, privileged women, frequently overlooking different convergences. As McCall (2005) clarifies, "It [is] unrealistic... to comprehend a people of color's understanding from past investigations of sexual orientation joined with past investigations of race on the grounds that the previous concentrated on white women and the last on individuals of color" (p. 1780). Additionally, it is beyond the realm of imagination to expect to comprehend the encounters of queer women of color while depending exclusively on past exploration in sex, ethnic, or queer examinations without representing the manners in which that those characters converge. Earlier writing hence offered little space for nonwhite lesbians to investigate their different convergences (Parks et al., 2004), leaving lesbians of color feeling secluded from the standard queer network (Leslie and MacNeill, 1995). Fortunately, basic social (eg, Calafell, 2013), intercultural (eg, Yep, 2010), and, most as of late, family (eg, Suter, in press) correspondence researchers have been supporting for increasingly comprehensive grant that 
represents minimized encounters with the goal that queer individuals, ethnic minorities, queer non-white individuals, and queer women of color can have a space to represent themselves. That's right (2010) keeps up that intersectional work is regularly all the more testing be that as it may, "can deliver more nuanced, more extravagant, and increasingly many-sided research that catches the exemplifications and lived encounters of people and gatherings possessing various characters... at a specific crossroads in history and international area" (p. 174). This move toward regarding the accounts and novel encounters of queer women of color gives a space to take part in this current examination, which considers the stories of a queer Iranian woman who is an English teacher in an English institution in south east of Iran. Her sexual and social identity are apparently inconsistent.

\section{Literature Review}

As per Erikson (1968), knowing oneself and encountering coherence is basic for people to encounter prosperity. Campbell (1990) characterizes self-idea lucidity, or identity clearness, as the degree to which one's self-convictions are unmistakably and unhesitatingly characterized, inside steady, and stable. Through her exploration, Campbell found that character lucidity was emphatically identified with confidence, while different researchers keep up that personality clearness is critical for mental working (eg, Sheldon, Ryan, Rawsthorne, and Ilardi, 1997). Analysts have in this manner started analyzing aggregate character lucidity to more readily comprehend which bunch enrollments, or other social identity, identify with individual identity and to prosperity results.

People ordinarily see themselves as far as their gathering enrollment classifications, to such an extent that one's gathering membership(s) become a key segment of their individual identity (Turner, 1982). These self-conceptualizations are gained and created through people's connections with others and are impressively impacted by people's social socialization, family socialization, cultural assimilation and identity change forms (Ting-Toomey, 2005). Through this turn of events, the qualities, ideological positions, shared practices, encounters, and shared history that is related with one's group(s) become disguised by the person to make a vital segment out of a person's self-idea (Ashmore, Deaux, and McLaughlin-Volpe, 2004).

Significantly, grant has featured the manners by which assurance or lucidity of a person's aggregate identity is influenced by the standards that plague a person's social condition. Obviously, all people have different crossing identity bringing about some type of identity exchange, generally including contending social and social standards. For instance, Anzaldúa (1987) estimates a type of identity exchange by depicting borderlands, a psychological state or spot where bodies, accounts, identity, societies, sexualities, classes cover. Anzaldúa (1987) depicts la mestiza, a woman "Supported in one culture, sandwiched between two societies, riding every one of the three societies and their worth frameworks, la mestiza experiences... an internal war. Like others having or living in more than one culture, we get different, regularly restricting messages" (p. 78). Likewise, queer Iranian women are associated with different grating worth frameworks, and must figure out how to intentionally arrange their various social identities, cautiously, carefully, and purposely. 
As of late, analysts have endeavored to fill this hole in writing by investigating the impact of arranging various aggregate identity through aggregate identity mix. Aggregate character incorporation alludes to the compromise of various distinctive group or social personalities into their feeling of self (Amiot, De la Sablonniere, Terry, and Smith, 2007; Usborne and Taylor, 2010). Discoveries from this examination propose that the individuals who have coordinated integrated identities have more prominent mental prosperity (Benet-Martinez, Leu, Lee, and Morris, 2002; Berry, 2005). On the other hand, more prominent integrated identity impedance, when the standards and estimations of one integrated identity meddle with those of another, is identified with lower levels of prosperity (Settles, 2004). This exploration manufactures a solid case for the centrality of identity incorporation, yet neglects to completely address the one of a kind difficulties people experience when their crossing identity are apparently contradictory.

A few researchers have inspected integrated identity ambiguities. For instance, Jaspal and Cinnirella (2012) take a gander at the manners by which British Pakistani men who recognize as both Muslim and gay adapt to two conceivably inconsistent identities (ie, their religious identity and their sexual identity). Jaspal and Cinnirella (2012) clarify that there are sure translations of Islam that keep on concurring domineering status to heterosexuality and criminal homosexuality. Discoveries from their examination uncover a few systems for comprehension and characterizing these inconsistent identities (ie, comprehending the gay identity, summoning religious identity to clarify sexual identity, dread of perfect retaliation, and outside attributions and British national identity). Further, members in their examination portray a need to guarantee a feeling of rationality between these contradicting identity (Jaspal and Cinnirella, 2012).

The current investigation looks to develop existing writing by investigating the manners in which that queer Iranian women arrange being queer and Iranian. Significantly, while we battle that Islam can be utilized as a site of social information, likewise with any religion, to sum up a religious book with an end goal to induce a widespread moral code would be an insult to any religion or ethnic network. Or maybe, we can just consider explicit social translations of the Qur'an so as to talk about its impacts on that specific social code. In this way, the current investigation centers around the manners by which the Iranian ethnic identity (which incorporates religious impacts) and sexual identity converge.

\subsection{Iranian Discourse of Gender and Sexuality}

Regardless of the worldwide development toward more noteworthy acknowledgment of sexual minorities, five nations keep on condemning individuals to death based on sexuality: Mauritania, Saudi Arabia, Sudan, Yemen, and Iran (Itaborahy, 2012). Iran is a moderate Islamic nation with $98 \%$ of the occupants recognizing as Shi'a (CIA.gov, 2013). Because of the "codification of a specific translation of shari'a (Islamic law)" (Bucar and Shirazi, 2012, p. 418), Iran unequivocally denounces gay movement (Bucar and Shirzai, 2012; Simon and Brooks, 2009). As indicated by Bucar and Shirazi (2012), 
In the Iranian Penal Code, Articles 108-126 arrangement with the discipline for homosexuality (lavat in Persian and liwat in Arabic), characterized in Art. 108 as "sex with a male." Although discipline is in fact surrendered over to the circumspection of the shari'a judge (Art. 110, 120), for grown-ups, the most extreme discipline for consensual homosexuality is demise (Art. 109-111). (p. 418)

Also, for women,

Same-sex conduct between two women is managed in Articles 127-134 of the Iranian Penal Code. The law characterizes lesbianism, alluded to as mosaheqeh in Persian, as "same-sex connection between women with genital contact" (Art. 127)... Punishment for female-female sex acts, be that as it may, contrasts from homosexuality: the initial multiple times it is demonstrated in court by four observers (Art. 128), 100 lashes are endorsed for each gathering included (Art. 129). The fourth time the demonstration is demonstrated in court, the punishment is death (Art. 131). (Bucar and Shirazi, 2012, p. 418)

As showed by the guiltiness of gay movement, Iranian social discourse regularly dismisses the authenticity of queer identities. Specialists deny that gay Iranians even exist. For instance, in 2007, previous Iranian President, Mahmoud Ahmadinejad freely condemned the whole thought of homosexuality asserting that "the wonder" doesn't/won't/can't exist inside the Islamic Republic of Iran.

Alongside prevailing discourse privileging heterosexuality, Iran additionally holds fast to unmistakable and recognizable sex jobs existing inside a man centric order that favors men in almost all parts of public activity. This awkwardness leaves queer Iranian women to confront an assortment of extra social and familial difficulties (Bucar and Shirazi, 2012; Van Gilder and Abdi, 2014). For example, since family is viewed as essential for social dependability, queer women from Middle Eastern and North African foundations frequently experience "pressure from their families to follow standardizing sexual orientation jobs" (Al-Sayyad, 2010, p. 380). Therefore, Iranian families frequently constrain women to wed at a fitting age and reproduce rapidly (Abdi, 2014; Al-Sayyad, 2010; Parnian, 2006). Declining to do so brings about lost status (Parnian, 2006) along these lines giving queer Iranian women the troublesome decision to either conform to her folks' desires to wed, or uncover her sexuality (Yip, 2004).

We contend that the Iranian identity capacities at numerous crossing points since it very well may be viewed as an ethnic, social, national, and racial identity. In this way, the prevailing discourses and heterosexist philosophies depicted above do not really mirror those all things considered. Truth be told, numerous Iranian women decipher or comprehend their Iranian way of life as having pretty much nothing or nothing to do with religious practices, the same number of Iranian families living outside of Iran do not effectively participate in Islamic practices (Mobasher, 2006). All things being equal, isolating Islamic qualities from Iranian culture is not simple, the same number of the common accounts that shape Iranian identity are inseparably connected to explicit translations of Islam. In this way, this study centers around ethnicity instead of religious identity to all the more precisely speaks to participant's self-ID. 


\subsection{Community and Social Help}

As indicated by Buber (1965) some type of network is important to make life worth living. Further, sentiments of gathering connectedness, pride, and positive effect toward the gathering positively affect people's confidence (Ghavami, Fingerhut, Peplau, Grant, and Wittig, 2011).

On the other hand, the nonattendance of network can make a void-sentiments of seclusion and flimsiness (Rosenthal, 1984). Without solid connections to social networks, especially bunches in which individuals share certain identity qualities; people regularly face an expanded danger of misery, antagonistic self-idea, and diminished physical and emotional wellness (Ghavami et al., 2011). All things considered, queer Iranian women are needing encouraging groups of people that advance mental prosperity and confidence.

Sadly, in light of the fact that not many accounts of queer Iranian women are made open (Abdi, 2014), LGBTQ Iranian regularly come up short on a feeling of having a place ("LGBT Republic," 2012). Further, Iranian social discourses regularly fill in as a type of rambling viciousness against the individuals who do not fit the heteronormative command (Yep, 2003). As Yep (2003) clarifies,

Early in life youngsters gain from relational contacts and intervened messages that deviations from the heteronormative norm, for example, homosexuality, are uneasiness ridden, blame creating, dread slanting, disgrace conjuring, abhor meriting, mentally blemishing, and truly undermining. (p. 21)

Queer Iranian women are regularly prevented any sense from claiming network or having a place (Ghavami et al., 2011). Further, as Chávez (2010) clarifies, sentiments of prohibition might be more grounded for workers or original Americans, as settlers (and queer individuals) have consistently been barred from completely having a place with the U.S. country state.

Van Gilder and Abdi (2014) explain that an absence of social help from family and additionally different individuals from the ethnic network can regularly deny LGBTQ ethnic minorities of a significant social and familial emotionally supportive network. This turns out to be particularly tricky when guardians cling to the predominant social convictions toward homosexuality. As analysts have discovered, parental help positively affects the mental improvement of LGBTQ people (Carrion and Lock, 1997; Coleman, 1982). On the other hand, family dismissal of people's sexual characters is identified with more serious dangers for sadness, self-destructive ideation, substance misuse, disguised homophobia, identity disarray, disgrace uneasiness, dread, coerce, and diminished psychological well-being (Ryan, Huebner, Diaz, and Sanchez, 2009; Van Gilder and Abdi, 2014; Willoughby, Doty, and Malik, 2010). In any case, these impacts might be affected (decidedly or contrarily) by common, familial, and social collaborations. Along these lines, this investigation looks to reveal the manners by which Iranian social talks may impact sentiments of having a place for eccentric Iranian ladies, and the manners in which that queer Iranian women adapt to heteronormative discourses.

As women's activist intercultural specialists, the analyst have a personal stake in giving 
Iranian queer women the space to change discourses about their identity through the narratization of their own lives. Further, it is basic to be straightforward about my own positionalities when leading this examination, on the grounds that as Calafell (2013) keeps up, "these spaces, in their multifaceted nature and variety, call us to be responsible to other people and to ourselves in denoting the functions of intensity" (p. 7). My expectation for this article is to reveal insight into strange bodies that are frequently ignored in discussions about Iranian queer women, explicitly inside communication and applied linguistics studies.

\section{Method}

\subsection{Research Questions}

In this way, the accompanying examination questions are presented:

RQ1: How does Iranian social, familial, and social discourse impact sentiments of having a place for queer Iranian women?

RQ2: How queer Iranian women adapt to the difficulties of being LGBTQ recognized in the Iranian society?

\subsection{Participants}

Before any endeavor to investigate the instruments of intensity in building educators' characters, I attempt to focus on my participants close to home and expert narratives. It is huge to take note of that the social and personal surface of the member's educational encounters can help us in our endeavor to uncover the prevailing discourse that have been continually molding and reshaping her character. In their longitudinal investigation on instructors, I concur with Flores and Day (2006) on the critical effect of educators 'individual and expert setting as deciding components on their identity.

\subsubsection{Participant's Background}

The participant of the study is an English teacher who teaches at an English institution in Iran. She is named Pariya after this. Pariya hold a MA degree in English language teaching. She is 32 years old and she is also single. She was born and raised in south east of Iran. Her native language is Farsi. Pariya realized that she is a lesbian when she was 18 years old and already turned down a marriage proposal which upset her family especially her father who threatened her that he would kill her if she decides to pull the same thing with the next marriage proposal. Pariya grew up in an extremely religious family in which her father words meant everything in the family. But it was impossible for pariya to come out to her family because she was sure that her father and brothers would kill her. So she decided to keep her sexual orientation a secret and just keep refusing to get married because she could not stand the thought of being married to a man. On the other hand, homosexuality is considered as a crime and the punishment for it is death in Iran. Hence, if anybody knew that she was a queer she would have ended up dead anyway.

It was an impossible situation that she was stuck in. until she went to university and she fell 
in love with her female classmate named Mina and after a while they realized that the feeling was mutual. They started spending a lot of times together but unfortunately one time that they were in Mina's house, her brother saw them together which was a disaster because mina's situation and many other woman's situation in Iran is the same as Pariya's. The next day mina's brother threw acid on Pariya which caused her seven different surgeries just to keep her alive. Almost 10 years has passed from that day and half of her face is distorted and her left hand's nerves were all destroyed by the acid. However, to this day she could not tell anyone that she knew who did this to her because she would be killed by her family or the government. She stayed silent and she just remembers Mina's brother voice telling her that in this way she would not be able to corrupt other women ever again. After 5 years from that horrible event, Pariya went to university again to get her MA degree and to this day she is trying to put this all behind her but she says it is impossible because he turned me into this monster that sometimes even scares me when I look at the mirror. But she became an English teacher in an English institution in their town and even though nobody knows about what actually happened and the reason behind it, being in the class makes her feel free and more like a human being. She asserted "it takes a while in each class for students to be able to ignore my distorted face and actually listen to me but it was a very unfair price that I had to pay just for bring a lesbian. Of course, now I am desexualized because people can barely stand look at my face after that cursed day." She continues: "I am a stranger where ever I go especially when I am among my colleagues. They talk about their relationships and their challenges which make them become closer and make friends but all I feel is the need to stay as far as possible so nobody ever knows that I am a homosexual. Sometimes I wish I was not the way that I am. This whole thing makes me wish that I was straight or I wish I did not fall for a girl or I wish I ignored my feelings and listened to my father and got married at least in this way I still had a face. All I'm saying is that it gets very lonely living my life."

\subsection{Data Collection}

The data for this qualitative examination was gathered through narratives. Narratives have gotten a lot of consideration over the previous decade and speak to the primary collection of information for contemplating instructor character. As indicated by Barkhuizen, Benson, and Chik (2014), stories are helpful devices in instructor personality research since they "catch the nature and significance of encounters that are hard to watch legitimately and are best comprehended from the point of view of the individuals who experience it" (p. 8). They likewise permit educators to view themselves as and their activities as socially and truly arranged (Johnson and Golombek, 2002).

So as to get educator's narratives, 7 interviews were led with the participant. Each meeting kept going an hour. The meetings were led in Farsi language and afterward were converted into English. The deciphered writings were alluded back to the interviewee to be checked for precision of expected messages and implications.

\subsection{Data Analysis}

The data of instructor's accounts were broke down by utilizing constant comparative strategy (Glaser and Strauss, 1967). In steady similar technique, the scientist creates topics and ideas 
by coding and dissecting the information simultaneously (Taylor and Bogdan, 1998). The accompanying advances were taken to examine the meetings. Stage 1 included Organizing and setting up the information for examination by deciphering the meetings arranging and orchestrating the information into various sorts as indicated by the various wellsprings of data. Step2 included the perusing all the information and getting its general feeling. Stage 3 included beginning the coding of the information by arranging the information in sections or lumps. Stage 4 included utilizing codes to create subjects and revealing them. In sync 5, the specialist put the topics in accounts. The last advance included deciphering the information dependent on the individual experience and past writing (Creswell, 2014). To guarantee believability of the coding, the information were coded by another autonomous coder and Cohen "es Kappa coefficient was applied to the outcomes which created bury coder unwavering quality of .90 . Also, the legitimacy of the discoveries was checked by utilizing member checking. The member instructor was approached to peruse the subjects and assess the precision of the outcomes. This area incorporated an extra meeting with the member. The consequences of this meeting were applied in concluding the discoveries.

\section{Result and discussion}

\subsection{Homosexuality Identity Delegitimization}

Discoveries uncover that Iranian social discourse present homosexuality as a demonstration, an ailment, or as a decision, yet once in a while as a piece of one's center being. By preventing the authenticity from claiming the homosexual identity, prevailing social discourse work to separate the queer way of life as basically a brief or reparable blemish, something that can be fixed or expelled from the body. Thusly, predominant social discourse keep on stifling discourse about the personalities of sexual minorities. Homosexual identity are delegitimized in two unmistakable manners: (1) by confining homosexuality as an "illness" and (2) by encircling homosexuality as a "Western marvel."

\subsubsection{Homosexuality as a Ddisease}

The primary classification that rose was homosexuality as a sickness. Pariya expressed that:

"While I was growing up I was so convinced that homosexuality is an illness in people's mind because my family believed in it with their whole being. It was like a proven fact to us and we were taught in school that homosexuality is the main reason to catch an incurable and horrible disease such as AIDS. Hence, I was so convinced that being gay or lesbian is a nasty illness and of course there was the government decision on ultimate punishment of homosexual people which was death. Every corner that I looked was and still is ugliness related to homosexuality. So you could not imagine the shame that I felt inside me when I realized that I liked women but I was a women too and I was sure that I was not ill in the mind or a nasty creature, I just liked women that's all."

Iranian social discourse not just propagates ideas of homosexuality as a physical sickness, much like malignant growth or AIDS, yet additionally marks it a mental disease that may 
have come about because of a horrendous sexual encounter. Predominant discourse inside the Iranian people group sustain ideas of homosexuality being an infection or malady, as something to be relieved or expelled from the body. The member in the investigation finds out about homosexuality just as a deformity, instead of as a worthy sexual identity with LGBTQ people regularly being alluded to in the past tense. This perspective is additionally confirmed by the expressions of Iran's Secretary-General of Human Rights, Dr. Larijani, who declared, "the West says that the marriage of gay people ought to be permitted under the human rights sanction, be that as it may, we [ie, Iranian officials] think it is extramarital perversion and a sickness" (Littauer, 2012). Such discourses work to delegitimize the sexual identity of LGBTQ Iranians.

\subsubsection{Homosexuality as a Western Wonder}

The second class of homosexual identity delegitimization is homosexuality as a Western marvel. The participant clarified that homosexuality is said not to exist as a genuine sexual identity; rather it is seen as a decision. In these cases, homosexuality is confined as a decision made by degenerate Westerners, or all the more explicitly, as a Western wonder. For example, Pariya mentioned:

"You know the part that is really hard to believe for me is that everybody acts like that homosexuality belongs to people who live abroad and Iranians are waterproof against this so called god forbidden illness. As long as I remember Iran has never been in good terms with western countries specially USA so it sounds so convenient that government try to pin this so called horrible disease to western countries. Government even announced that homosexuality does not exist in Iran and this is only a western illness so Iranian can feel safe and know for sure that nothing regarding this matter is threatening them."

This finding is steady with past writing. Truth be told, a few scientists have detailed that homosexuality is broadly seen by the Islamic people group as a "Western malady" (ie, Siraj, 2011; Yip, 2004). In addition, Yip (2004) has noticed that to be Iranian and homosexual is seen just like "a survivor of "westoxication" (being inebriated by mainstream Western culture)" (p. 340). Indeed, even the couple of Iranian priests who do recognize the simple presence of queer bodies inside the Islamic Republic of Iran quite often give them a role as the Western "other" (Korycki and Nasirzadeh, 2011).

The prevailing discourse inside the Iranian people group can have inconvenient results on the self-ideas and prosperity of queer Iranians as they battle with their own sexual and ethnic identity. These discourses work as a wellspring of identity delegitimization by excusing homosexuality as a Western wonder, or decision, as opposed to an identity.

\subsection{Cultural Isolation}

The social messages about homosexuality persistently propagated inside the Iranian people group essentially sway sentiments of having a place for queer Iranian women. Truth be told, the member of the investigation detailed sentiments of social detachment, in that her sexual and ethnic identity were legitimately at chances with each other or potentially she felt alone and imperceptible in her own ethnic network. In that capacity, the member of the 
investigation feels that she cannot be Iranian and queer simultaneously. Social seclusion involves two primary classifications of experience: (1) identity dissonance and (2) perceived invisibility.

\subsubsection{Identity Dissonance}

The participant of the examination revealed encounters of personality disharmony. She depicts sentiments of character strife where her ethnic and sexual personalities are straightforwardly at chances with each other. Pariya portrays this inclination expressing,

"No matter where I am I always feel like an alien. I cannot relate to people and make close friends. It's like I came from outer space and watching other people living their lives and for a moment I want to be exactly like them. I want to tell them that I am a homosexual. I really like to fall in live and marry a pretty woman and have kids. Just like what my friends did but $\mathrm{i}$ remember in Iran I'm not supposed to exist. Homosexuality according to our government does not exist in Iran. So what the hell I am then? I exist and I am real. Of course these are things that going on in mind, I never dare to talk about my desires and sexuality. I never did. In my entire life I came out to only one person, my first love, Mina and as a result her brother turned me to this monster. It is impossible to be homosexual and Iranian at the same time; otherwise, you have to pay the price like I did. Knowing English language and watching western movies and reading their books helped me to realize that there is a world out there that I could belong to where I could make my own family with my wife but that place is definitely not Iran. As an English teacher, we are not allowed to teach or to talk much about the culture related to English language in the class because it goes against the government wishes. In the eyes of the government we are trying to corrupt students minds with western culture so we just skip this part. Therefore, it feels really off in the class too. As an English teacher I feel more related to western countries culture than Iranian ones. Iranian culture has nothing for homosexuals but horrible judgments and punishment. On the other hand, in many western countries such as USA homosexuals can marry each other and have a normal life. I wish I was born there."

Pariya's depiction embodies the disharmony that she feels as she attempts to explore between her two oppositely contradicted identity. This turns out to be particularly testing as she arranges her identity in a social space where homosexuality is apparently nonexistent. For the participant, identity congruity has not, or can't be accomplished, as social talks work to break her characters into contending parts. As past writing has reported, such identity disjointed qualities can be adverse to people's general feeling of prosperity.

\subsubsection{Perceived Invisibility}

The second class that includes social seclusion is seen intangibility. Not exclusively queer Iranian women experience discord as they ceaselessly explore between two apparently inconsistent social universes, yet they experience sentiments of being undetectable and alone. For example, Pariya says,

"Sometimes when I think how far our government is willing to go just to prove the point that homosexuals do not exist in Iran, makes me wonder that maybe they are right and I am wrong 
about being a lesbian and maybe my sexuality does not really exist. Otherwise, why everyone in Iran is agreeing with this statement that homosexuality does not exist in our country. Of course all these thoughts go away when I secretly fell in love with a pretty woman who has no idea about my feelings. Then I think if every queer in this country is hiding his /her sexual identity, how I can ever know that they do exist. I think denying the existence of our kind is a cunning strategy from our government corner, so we start to doubt ourselves or our sanity one way or the other. It almost worked on me, I always feel lonely and depressed. I have got no body to talk to about my real feelings. I cannot tell a soul what is really going on with me. Of course now that I look like a monster nobody sees me as a sexual being anymore. Maybe it is for the best. At least I do not have to pretend that I like men and being forced to marry them. Now, nobody wants me. I am officially an invisible nonexistent being. In this utter loneliness, you do not have a support system or a role model to rely on. It's just you and your shameful thoughts about your sinful existence."

As clarified in the previous area of the examination, Iranian social contents portray homosexuality as a Western wonder. The absence of social portrayal of queer Iranians makes a bogus thought that homosexuals do not exist, especially inside the Iranian society. Thus, queer Iranian women experience sentiments of seclusion, like there are no other queer Iranians with whom they share a comparative encounter. These sentiments of intangibility portrayed above are additionally upgraded by the absence of assets accessible to queer women inside the Iranian society.

These sentiments of detachment make a requirement for social help, which queer Iranian regularly cannot get from those inside the Iranian society. This absence of help or acknowledgment can possibly thwart fruitful identity advancement for LGBTQ recognized Iranian women.

\subsection{Creating Cultural Distance}

To address the subsequent exploration question, I solicited the participant from the investigation how she adapts to the difficulties of being both queer and Iranian. Discoveries uncover that she endeavors to make social separation as a way of dealing with stress to counter sentiments of confinement. This is done in two different ways: (1) by smothering social distinguishing proof and (2) by looking for help from social pariahs.

\subsubsection{Suppressing Cultural Identification}

Stifling social recognizable proof alludes to the separating of oneself from distinguishing proof with Iranian culture, or the way of life wherein sentiments of disconnection are experienced. Strangely, the concealment of social distinguishing proof announced during interviews was depicted as being both physical and emotional. For instance, Pariya says:

"I was almost 18 years old when I realized that I was a lesbian. Of course I experienced couple of crashes for my female teachers before but I did not know what was going on with me. But it sounded so weird when I wanted to talk about it with my friends until eventually I figured out what was all those feeling about and started to distant myself from my friends and just avoid the so called weird conversations about my loved ones. Almost everybody around 
in our class had a boyfriend or desperately wanted to have one but it all seemed so meaningless to me. I always thought who wants to date stupid guys. My friends used to call me a nun because I had no desire to date boys and I thought it is for the best for them to think like that I was just more comfortable avoiding the company of my friends to the point that by graduation I lost them all. I mean we were like regular classmates just saying hi to each other in the mornings. So the last year of high school my books and my dreams of saving myself from all those nonsensical Iranian traditions were my closest friends. The truth was I was not part of the Iranian culture and traditions. They did not define any place for queer people. It was like we did not exist in their eyes so I made up my mind to do the same to them. I mean the Iranian so called culture; I isolated myself from my friends and my family both emotionally and physically. I did not want to have anything to do with them because I know they would throw me out like trash if they knew I was a queer. All those pressure built on me made me feel angry all the time and every corner that I looked there was my father reminding me that I was getting old and I needed to get married which sounded disgusting to me because I had to spend the rest of my life with a man that I had no feelings for."

The member of the examination features an outside adapting system, through which she genuinely isolated herself from the ethnic network in which she encountered estrangement. Alongside physical division, the member likewise portrayed a passionate concealment of social recognizable proof. Pariya portrayed an inside adapting system. She clarified that, now and again, she endeavors to shed her way of life attributable to the passionate detach between her own convictions, qualities and perspectives, and those that she saw to be related with Iranian culture. These discoveries are reliable with past examination. For example, Yip (2004) clarifies that numerous nonheterosexuals isolate themselves from their families when confronted with prejudice or dismissal. This separation gets clear in this examination as the member adapt by separating herself from the Iranian people group where she feels curbed or disengaged. This selection subsequently shows the manners by which Pariya endeavored to separate herself from the Iranian culture as methods for adapting to sentiments of social seclusion.

\subsubsection{Looking for Help from Cultural Outsiders}

The participant of the examination looks for help outside of her Iranian people group, as she can act naturally just outside of her ethnic culture. For instance, Pariya states:

"To tell you the truth I became interested about English language learning and later teaching it mainly because it connected me to the cultures of the countries in which being a queer is celebrated and they are allowed to be themselves and have their circle of friends and family whom they can trust and rely on. So I decided to choose it as my university major as well hoping to meet with people who also were exposed to English speaking culture so I can finally make a friend and have my own support system. of course it did not go as I expected but I was not willing to quit yet. Online chatting was not very popular those days; there were only yahoo messenger's chat rooms that could connect me to those cultures outside my own country. For a while I tried and I could not connect to any one online deep enough to start to talk about my issues and I was getting disappointed until I started to chat with an American 
woman named Alex. To my own surprise we became friends and eventually I talked about my feelings with her and she talked about her brother who was gay and how her family embraced the whole thing and made him feel belong and so comfortable. Finally I found my support system, my actual friend whom I never met face to face. It was great for me at the time and she actually supported me to build up the courage to tell Mina my first actual love that how I felt about her. Everything was awesome until the day that the monster threw acid on me. I did not talk to Alex after the incident because I was always in the hospital and depressed and hurt that I did not want to talk to anyone. So I lost her too."

This is reliable with Yip's (2004) discoveries, as he clarifies that despite dismissal, it is not exceptional for nonheterosexual people to develop their own encouraging groups of people outside of their families. Significantly, the adapting systems depicted by Pariya in this investigation may empower queer Iranian women to encounter having a place and find new networks that encourage positive identity improvement in spite of social discourse of dismissal.

\section{Conclusion}

The objective of this investigation was to look at (a) how Iranian social discourse impacts sentiments of "having a place" for queer Iranian women, and (b) how queer Iranian women adapt to the difficulties of being LGBTQ and Iranian. Grounded theorizing addressed these inquiries, and our discoveries uncover that queer Iranian women experience sentiments of social seclusion because of the homosextual identity delegitimization that overruns Iranian social discourse. Thusly, queer Iranian women endeavor to adapt by making social separation among themselves and the Iranian people group in which they experience this detachment.

Queer identity are delegitimized in two unmistakable manners: (1) by surrounding homosexuality as an "infirmity" and (2) by confining homosexuality as a "Western marvel." Not just did the member of the investigation depicted discovering that homosexuality was an infection, yet in addition she detailed learning at an early stage in her life that homosexuality was a result of Westernization, as homosexuality was said not to exist inside the Iranian people group. This prevailing social discourse keeps on mistreating and delegitimize the identity of sexual minorities, which does not furnish the member of the examination with the identity certification that she required for sound character advancement. Because of this identity delegitimization, the member of the examination announced sentiments of social separation.

Social disconnection contains identity cacophony and saw intangibility. This intangibility is then disguised as member's vibe as though she is distant from everyone else in her encounters. These sentiments of disconnection make a requirement for social help, which queer Iranian women frequently cannot get from those inside the Iranian society. So as to adapt to the difficulties of being eccentric, the member of the examination endeavored to make social separation by smothering social ID and by looking for help from social untouchables. She noticed the significance of identity insistence and many acknowledge that their sexual 
identity may not be acknowledged as well as positively esteemed inside her ethnic network. In that capacity, the member of the examination looked for this insistence somewhere else by separating herself from her social networks and by looking for help from non-Iranians.

\section{References}

Abdi, S. (2014). Staying I(ra)n: Narrating queer identity from within the Persian closet. Liminalities: A Journal of Performance Studies, 10(2), 1-20. Retrieved from http://liminalities.net/10-2/staying.pdf

Al-Sayyad, A. A. (2010). You're what?": Engaging narratives from diasporic Muslim women on identity and gay liberation. In S. Habib (Ed.), Islam and homosexuality, volume 2 (pp. 373-394). Santa Barbara, CA: ABC-CLIO.

Amiot, C. E., De la Sablonniere, R., Terry, D. J., \& Smith, J. R. (2007). Integration of social identities in the self: Toward a cognitive-developmental model. Personality and Social Psychology Review, 11(4), 364-388. https://doi.org/10.1177/1088868307304091

Anzaldúa, G. (1987). La conciencia de la mestiza: Towards a new consciousness. In Borderlands: The new mestiza $=$ La frontera (pp. 99-112). San Francisco: Spinsters/Aunt Lute.

Ashmore, R. D., Deaux, K., \& McLaughlin-Volpe, T. (2004). An organizing framework for collective identity: Articulation and significance of multidimensionality. Psychological Bulletin, 130, 80-114. https://doi.org/10.1037/0033-2909.130.1.80

Barkhuizen, G., Benson, P., \& Chik, A. (2014). Narrative inquiry in language teaching and learning research. New York: Routledge/Taylor \& Francis. https://doi.org/10.4324/9780203124994

Beck, C. T. (2005). Benefits of participating in Internet interviews: Women helping women. Qualitative Health Research, 15(3), 411-422. https://doi.org/10.1177/1049732304270837

Benet-Martinez, V., Leu, J., Lee, F., \& Morris, M. W. (2002). Negotiating biculturalism: Cultural frame switching in biculturals with oppositional versus compatible cultural identities. Journal of Cross-Cultural Psychology, 33, 492-516. https://doi.org/10.1177/0022022102033005005

Berry, J. W. (2005). Acculturation: Living successfully in two cultures. International Journal of Intercultural Relations, 29(6), 697-712. https://doi.org/10.1016/j.ijintrel.2005.07.013

Buber, M. (1965). Between man and man. New York, NY: Macmillan.

Bucar, E. M., \& Shirazi, F. (2012). The "invention" of lesbian acts in Iran: Interpretative moves, hidden assumptions, and emerging categories of sexuality. Journal of Lesbian Studies, 16(4), 416-434. https://doi.org/10.1080/10894160.2012.681263

Calafell, B. M. (2013). (I)dentities: Considering accountability, reflexivity, and 
intersectionality in the I and the we." Liminalities: A Journal of Performance Studies, 9(2), 6-13. Retrieved from http://liminalities.net/9-2/calafell.pdf

Campbell, J. D. (1990). Self-esteem and clarity of the self-concept. Journal of Personality and Social Psychology, 59, 538-549. https://doi.org/10.1037/0022-3514.59.3.538

Carrion, V. G., \& Lock, J. (1997). The coming out process: Developmental stages for sexual minority youth. Clinical Child Psychology and Psychiatry, 2(3), 369-377. https://doi.org/10.1177/1359104597023005

Central Intelligence Agency. (2013). Iran. The World Factbook. Retrieved from https://www.cia.gov/library/

Charmaz, K. (2006). Constructing grounded theory. Thousand Oaks, CA: Sage.

Chávez, K. R. (2010). Border (in)securities: Normative and differential belonging in LGBTQ and immigrant rights discourse. Communication and Critical/Cultural Studies, 7(2), 136-155. https://doi.org/10.1080/14791421003763291

Christians, C. G., \& Carey, J. W. (1989). The logic and aims of qualitative research. In G. Stempel \& B. Westley (Eds.), Research methods in mass communication (2nd ed., pp. 354374). New York, NY: Prentice Hall.

Coleman, E. (1982). Developmental stages of the coming-out process. American Behavioral Scientist, 25(2-3), 469-482. https://doi.org/10.1177/000276482025004009

Creswell, J. W. (2014). Research Design: Qualitative, Quantitative, and Mixed Methods Approaches. Los Angeles: Sage Publication.

Crenshaw, K. (1991). Mapping the margins: Intersectionality, identity politics, and violence against women of color. Stanford Law Review, 43(6), 1241-1299. https://doi.org/10.2307/1229039

Erikson, E. H. (1968). Identity: Youth and crisis. New York, NY: Norton.

Ghavami, N., Fingerhut, A., Peplau, L.A., Grant, S.K., \& Wittig, M.A. (2011). Testing a model of minority identity achievement, identity affirmation, and psychological well-being among ethnic minority and sexual minority individuals. Cultural Diversity and Ethnic Minority Psychology, 17(1), 79-88. https://doi.org/10.1037/a0022532

Holling, M. A., \& Calafell, B. M. (2011). Latina/o discourse in vernacular spaces: Somos de una voz?. Lanham, MD: Lexington Books.

Itaborahy, L. P. (2012). State sponsored homophobia: A world survey of laws prohibiting same sex activity between consenting adults. The International Lesbian, Gay, Bisexual, Trans and Intersex Association. Retrieved from http://old.ilga.org/

Jagose, A. (1996). Queer theory: An introduction. New York, NY: New York University Press.

Jaspal, R., \& Cinnirella, M. (2012). Identity processes, threat, and interpersonal relations: 
Accounts from British Muslim gay men. Journal of Homosexuality, 59(2), 215-240. https://doi.org/10.1080/00918369. 2012.638551

Korycki, K., \& Nasirzadeh, A. (2011). Desire recast: Production of gay identity in Iran. In APSA 2011 Annual Meeting Paper.

Leary, M. R., \& Kowalski, R. M. (1995). Social anxiety. New York, NY: Guilford Press.

Leslie, D., \& MacNeill, L. (1995). Double positive: Lesbians and race. In J. Adleman \& G. M. Enguidanos-Clark (Eds.), Racism in the lives of women: Testimony, theory and guides to antiracist practice (pp. 161-179). New York, NY: Haworth Press.

"LGBT Republic of Iran: An Online Reality?.” (2012). Small media reports. Retrieved from http:// issuu.com/smallmedia/docs/lgbtrepublic

Lindlof, T. R., \& Taylor, B. C. (2011). Qualitative communication research methods (3rd ed.).

Thousand Oaks, California: Sage.

Link, B. G., Cullen, F. T., Struening, E., Shrout, P. E., \& Dohrenwend, B. P. (1989). A modified labeling theory approach to mental disorders: An empirical assessment. American Sociological Review, 54, 400-423. https://doi.org/10.2307/2095613

Littauer, D. (2012, February 14). LGBT people are “diseased," says Iranian human rights official.

LGBT Nation. Retrieved from http://www.lgbtqnation.com/2012/01/lgbt-people-are-diseasedsays-Iranian-human-rights-offi cial/

McCall, L. (2005). The complexity of intersectionality. Signs: Journal of Women in Culture and Society, 30(1), 1771-1800. https://doi.org/10.1086/426800

Mills, J., Bonner, A., \& Francis, K. (2006). The development of constructivist grounded theory. International Journal of Qualitative Methods, 5(1), 1-10. Retrieved from http://www.ualberta.ca/ iiqm/backissues/5_1/pdf/mills.pdf

Mobasher, M. (2006). Cultural trauma and ethnic identity formation among Iranian immigrants in the United States. American Behavioral Scientist, 50(1), 100-117. https://doi.org/10.1177/0002764206289656

Moraga, C. (1997). La Güera. In C. Logan (Ed.), Counterbalance: Gendered perspectives on writing language (pp. 267-277). Ontario, Canada: Broadview Press.

Nakayama, T., \& Halualani, R. (2010). The handbook of critical intercultural communication. Chichester, West Sussex, UK: Wiley-Blackwell.

Parks, C. A., Hughes, T. L., \& Matthews, A. K. (2004). Race/ethnicity and sexual orientation: Intersecting identities. Cultural Diversity and Ethnic Minority Psychology, 10(3), 241-254. https://doi.org/10.1037/1099-9809.10.3.241 


\section{Macrothink}

Journal for the Study of English Linguistics

ISSN 2329-7034

2020, Vol. 8, No. 1

Parnian, H. (2006). The sexual rights of women and homosexuals in Iran. In S. Seidman, N. Fischer, \& C. Meeks (Eds.), Handbook of the new sexuality studies (pp. 325-329). New York, NY: Routledge.

Rosenthal, P. (1984). Words and values. Cambridge, England: Cambridge University Press.

Ryan, C., Huebner, D., Diaz, R. M., \& Sanchez, J. (2009). Family rejection as a predictor of negative health outcomes in white and Latino lesbian, gay, and bisexual young adults. Pediatrics, 123(1), 346-352. https://doi.org/10.1542/peds.2007-3524

Salganik, M. J., \& Heckathorn, D. D. (2004). Sampling and estimation in hidden populations using respondent-driven sampling. Sociological Methodology, 34(1), 193-240. https://doi.org/10.1111/j.0081-1750. 2004.00152.x

Settles, I. H. (2004). When multiple identities interfere: The role of identity centrality. Personality and Social Psychology Bulletin, 30(4), 487-500. https://doi.org/10.1177/0146167203261885

Sheldon, K. M., Ryan, R. M., Rawsthorne, L. J., \& Ilardi, B. (1997). Trait self and true self: Cross-role variation in the Big-Five personality traits and its relations with psychological authenticity and subjective well-being. Journal of Personality and Social Psychology, 73(6), 1380-1393. https://doi.org/10. 1037/0022-3514.73.6.1380

Sigel, P., \& Leiper, R. (2004). GP views of their management and referral of psychological problems: A qualitative study. Psychology and Psychotherapy: Theory, Research and Practice, 77(3), 279-295. https://doi.org/10.1348/1476083041839394

Simon, R. J., \& Brooks, A. (2009). Gay and lesbian communities the world over. Lanham, MD: Lexington Books.

Siraj, A. (2011). Isolated, invisible, and in the closet: The life story of a Scottish Muslim lesbian. Journal of Lesbian Studies, 15(1), 99-121. https://doi.org/10.1080/10894160.2010.490503

Suter, E. A. (in press). Introduction: Critical approaches to family communication research: Representation, critique, and praxis. Journal of Family Communication, 16.

Ting-Toomey, S. (2005). Identity negotiation theory: Crossing cultural boundaries. In W.B. Gudykunst (Ed.), Theorizing about intercultural communication (pp. 211-234). Thousand Oaks, CA: Sage.

Tracy, S. J. (2010). Qualitative Quality: Eight "Big-Tent" Criteria for Excellent Qualitative Research. Qualitative Inquiry, 16(10), 837-851. https://doi.org/10.1177/1077800410383121

Turner, J. C. (1982). Toward a cognitive redefinition of the social group. In H. Tajfel (Ed.), Social identity and intergroup relations (pp. 15-40). Cambridge: Cambridge University Press.

Usborne, E., \& Taylor, D. M. (2010). The role of cultural identity clarity for self-concept clarity, selfesteem, and subjective well-being. Personality and Social Psychology Bulletin, 36, 
883-897. https://doi.org/10. 1177/0146167210372215

Van Gilder, B., \& Abdi, S. (2014). Identity management and the fostering of network ignorance: Accounts of queer Iranian women in the United States. Journal of Intercultural Communication Research, 43(2), 151-170. https://doi.org/10.1080/17475759.2014.892895

Willoughby, B. L., Doty, N. D., \& Malik, N. M. (2010). Victimization, family rejection, and outcomes of gay, lesbian, and bisexual young people: The role of negative GLB identity. $\begin{array}{lllll}\text { Journal of GLBT } & \text { Family } & \text { Studies, } & \text { 6(4), }\end{array}$ https://doi.org/10.1080/1550428X.2010.511085

Yep, G. A. (2003). The violence of heteronormativity in communication studies. Journal of Homosexuality, 45(2-4), 11-59. https://doi.org/10.1300/J082v45n02_02

Yep, G. A. (2010). Toward the de-subjugation of racially marked knowledges in communication. Southern Communication Journal, 75(2), 171-175. https://doi.org/10.1080/10417941003613263

Yip, A. K. (2004). Negotiating space with family and kin in identity construction: the narratives of British non-heterosexual Muslims1. The Sociological Review, 52(3), 336-350. https://doi.org/10.1111/j.1467- 954X.2004.00483.x

Yum, Y. O., \& Hara, K. (2005). Computer-mediated relationship development: A cross-cultural comparison. Journal of Computer-Mediated Communication, 11(1), 133-152. https://doi.org/10.1111/j. 1083-6101.2006.tb00307.x

\section{Copyright Disclaimer}

Copyright for this article is retained by the author(s), with first publication rights granted to the journal.

This is an open-access article distributed under the terms and conditions of the Creative Commons Attribution license (http://creativecommons.org/licenses/by/3.0/). 